\title{
Evaluation of small-intestinal abnormalities in adult patients with Henoch-Schönlein purpura using video capsule
}

Henoch-Schönlein purpura (HSP) is a systemic vasculitis mediated by IgA and characterized by the clinical manifestations of nonthrombocytopenic palpable purpura, abdominal pain, arthritis, and renal disorder $[1,2]$. Gastrointestinal symptoms occur in up to $85 \%$ of patients with HSP and abnormalities may be observed throughout the gastrointestinal tract, especially in the small bowel [3]. The characteristics of the small-intestinal lesions in five adult patients with HSP were retrospectively

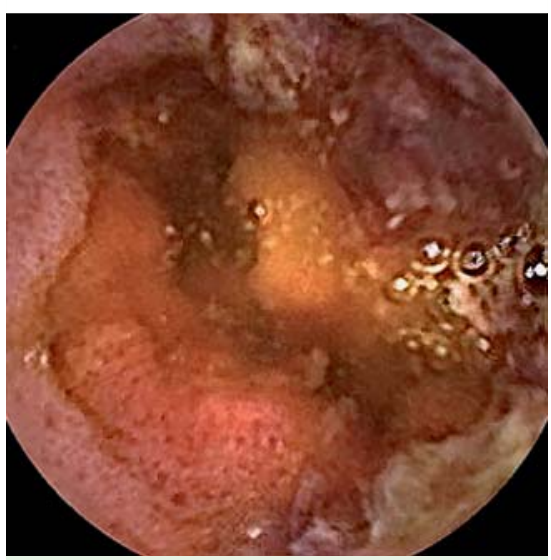

Fig. 2 Capsule endoscopic image of the ileum. An area of circumferential redness and edema, and an ulcer with mucus can be seen.

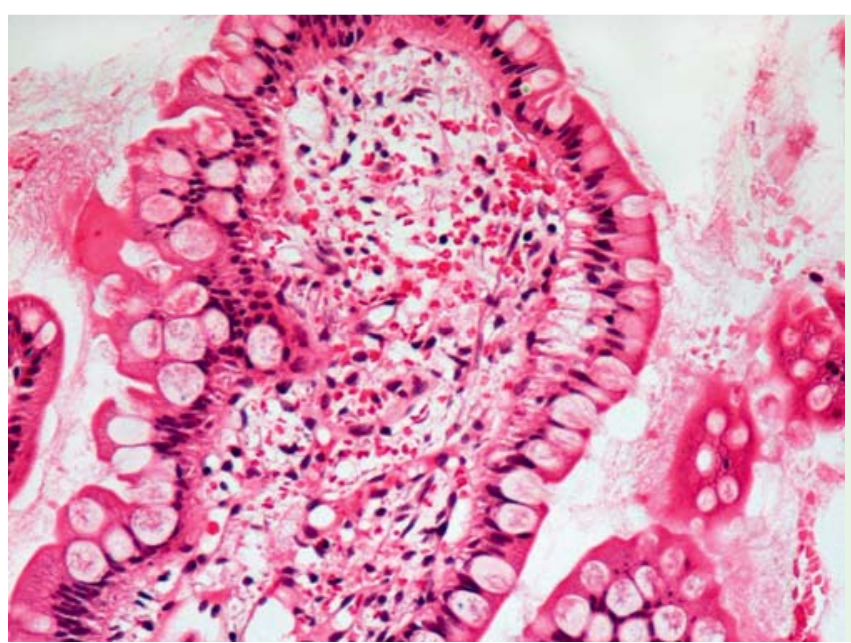

evaluated using video capsule endoscopy (VCE). None of the patients experienced any adverse events. In three of the five examinations, the battery of the VCE became exhausted before the device reached the cecum. It did however detect small-intestinal lesions in all cases. In contrast, for two of the patients computed tomography (CT) was able to detect only smallintestinal edema. VCE findings were classified as petechiae/redness, or erosions/ ulcers. Petechiae/redness, which was referred to as "intestinal purpura", was observed throughout the small intestine in all cases ( $\bullet$ Fig. 1). Erosions/ulcers were observed in four patients ( Fig. 2). A biopsy sample obtained by balloon enteroscopy from a petechial area showed extravasation of red blood cells in villi with mild inflammation ( $\bullet$ Fig. 3).

VCE is useful for comprehensive evaluation of small-intestinal HSP lesions that may not be detected by CT.

Endoscopy_UCTN_Code_CCL_1AC_2AD

Competing interests: None
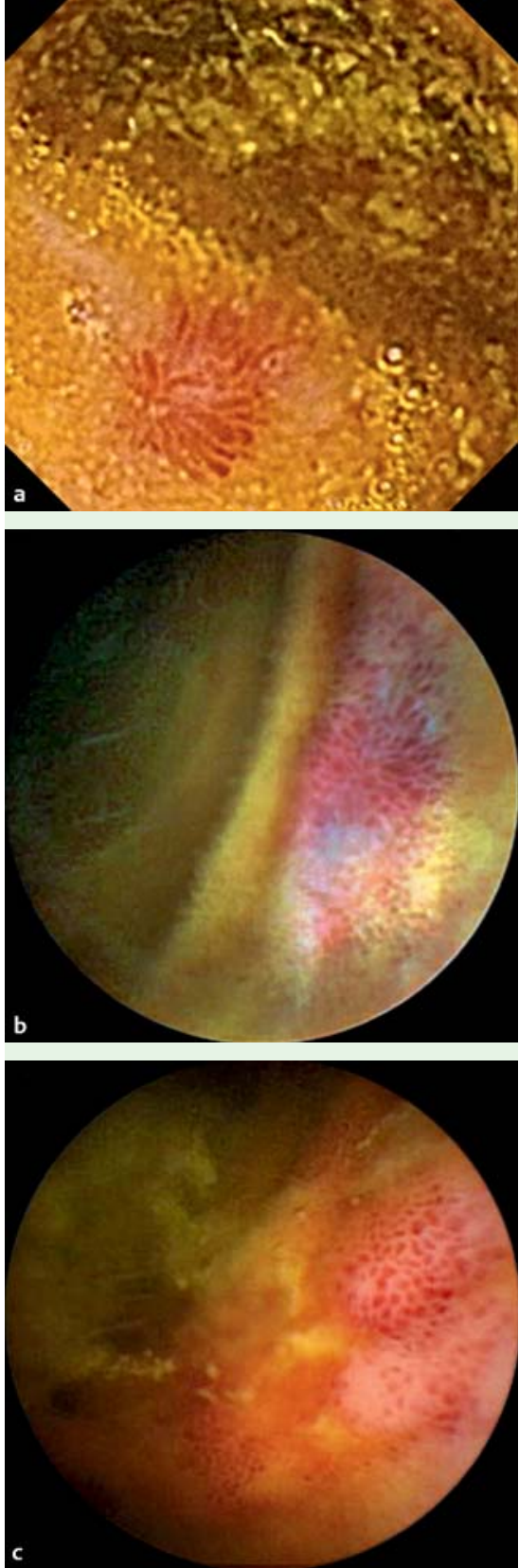

Fig. 1 a-c Three capsule endoscopic images, which show small-intestinal redness. These small reddish areas, which consist of intravillous hemorrhage with slight edema, were observed throughout the whole small intestine in all patients. 
R. Ichikawa ${ }^{1}$, N. Hosoe ${ }^{2}$, H. Imaeda²,

K. Takabayashi ${ }^{1}$, R. Bessho ${ }^{1}$, Y. Ida ${ }^{1}$,

M. Naganuma ${ }^{3}$, T. Hisamatsu ${ }^{1}$,

N. Inoue ${ }^{2}$, T. Kanai ${ }^{1}$, Y. Iwao ${ }^{2}$, M. Mukai ${ }^{4}$,

T. Hibi ${ }^{1}$, H. Ogata ${ }^{2}$

1 Division of Gastroenterology and Hepatology, Department of Internal Medicine, School of Medicine, Keio University, Tokyo, Japan

${ }^{2}$ Center for Diagnostic and Therapeutic Endoscopy, School of Medicine, Keio University, Tokyo, Japan

3 Department of Gastroenterology, School of Medicine, Tokyo Medical and Dental University, Tokyo, Japan

4 Division of Diagnostic Pathology, School of Medicine, Keio University, Tokyo,

Japan

\section{References}

1 Rodriguez-Erdmann F, Levitan R. Gastrointestinal and roentgenological manifestations of Henoch-Schönlein purpura. Gastroenterology 1968; 54: 260-264

2 Banerjee B, Rashid S, Singh E, Fitzgerald J. Endoscopic findings in Henoch-Schönlein purpura. Gastrointest Endosc 1991; 37: $569-$ 571

3 Preud'Homme DL, Michail S, Hodges C et al. Use of wireless capsule endoscopy in the management of severe Henoch-Schönlein purpura. Pediatrics 2006; 118: e904 - e906
Bibliography

DOI $10.1055 / \mathrm{s}-0030-1256266$

Endoscopy 2011; 43: E162 -E163

(c) Georg Thieme Verlag KG Stuttgart · New York . ISSN 0013-726X

\section{Corresponding author}

\section{H. Ogata, MD, PhD}

Center for Diagnostic and Therapeutic Endoscopy School of Medicine, Keio University

35 Shinanomachi, Shinjuku

Tokyo 160-8582

Japan

Fax: +81-3-3357-2778

hogata@z8.keio.jp 